\title{
Optimising the Erosional Performance of Store and Release Covers through Appropriate Landform Design
}

\author{
G. McPhail Metago Environmental Engineers, Australia
}

A. van Koersveld Metago Environmental Engineers, Australia

\section{INTRODUCTION}

Increasingly store and release covers are being provided to tailings, waste rock and heap leach facilities as part of the closure design with the purpose of controlling percolation of rainfall runoff through these facilities. While the focus in design is on the specification of the cover with respect to percolation performance, the success of the cover over the long term is highly dependent on erosional stability. But erosional stability is more than a question of maintaining cover thickness. As importantly, it is about ensuring that gulley formation within the cover as a result of rainfall runoff does not cut through the cover and expose the underlying tailings or rock materials, for it is at that stage that the cover could be regarded as having failed.

Long term landform modelling provides a useful engineering tool for assessing cover erosional performance especially where the model is able to simulate gulley formation. SIBERIA is one such model that has a proven track record. But it is the ability to carry out landform modelling in conjunction with landform engineering based on digital terrain models that ultimately provides the means to engineer for optimal cover performance beyond cover thickness determination.

This paper presents the results of the evaluation of a range of landform geometries and their performance using SIBERIA with the aim of developing broad guidelines on ways to maximise erosional performance of store and release covers through careful landform design. Both waste rock dumps as well as tailings storage facilities (TSF's) are considered.

\section{GUIDING PRINCIPLES FOR COVER DESIGN THAT EMERGE FROM LANDFORM EROSION MODELLING}

\subsection{Natural Analogues}

Natural analogues have proven useful in identifying the manner in which landforms naturally erode into catchments of limited size generating rounded, undulating topography of relatively flat slopes. A good erosion model will simulate erosion that will ultimately generate landforms that emulate natural landforms. However, unless the natural analogue comprises loose broken material similar to that of the proposed cover material there will be limitations with respect to the representativeness of natural landform profiles to dumps and tailings storage structures.

The most widely accepted erosion models are based on equations developed from river mechanics and embody concepts such as stream power and critical shear stress. These equations take the general form:

$$
Q_{s}=\beta_{1} Q^{m_{1}} S^{n_{1}}-\text { threshold }
$$

where $Q_{s}$ is the mean annual sedimentation rate, $\beta_{1}$ is the erodability factor (incorporating the material erodability, vegetation cover factor and any cropping practice factors (USLE terminology), $S$ the slope and $m_{1}$ and $n_{1}$ are parameters that will affect the rill spacing and concavity of the slope. For slopes of freshly placed materials $m_{l}$ and $n_{l}$ are generally greater than 1.5 and $n_{l}$ is usually greater than $m_{l}$.

There are therefore four parameters that combine to determine erosion and these parameters differ considerably for freshly placed materials compared with old ( $>5$ years) materials such as characterise mining structures and differ still further again from ancient materials such as found in natural landforms. The 
concept that the erosion parameters in equation 1 vary with time is not well appreciated or understood although research results are soon to be published (Willgoose, 2006) in this regard.

One valuable point to be taken from natural analogues is the general shape of an eroded slope. Nature will always tend to a slope geometry that minimises erosion. Concave slopes dominate naturally eroded landscapes in a direction parallel to the flow direction. It therefore follows that a concave profile with a rounded crest will tend to erode less than a single slope profile.

\subsection{Slope Areas}

Since the primary objective of a store and release cover is to reduce the net percolation entering a dump or TSF it is important to cover as much of the structure as practicable. It is often not appreciated that frequently slope areas make up more than $50 \%$ of the surface area of a dump or TSF. This is illustrated by Figure 1 which shows a range of dumps and TSF's and indicates the relative proportions of total area.

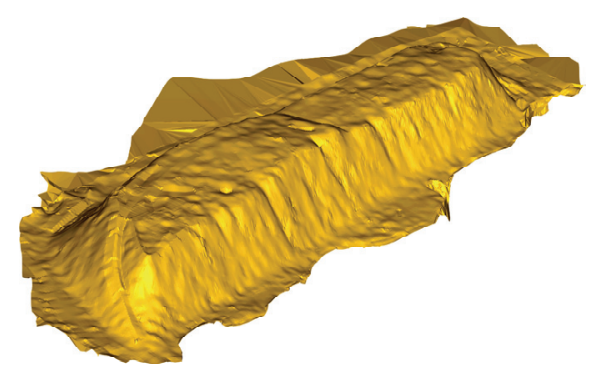

$\%$ Slope area of total area $=58.5 \%$

$\%$ flat area of total area $=41.5 \%$

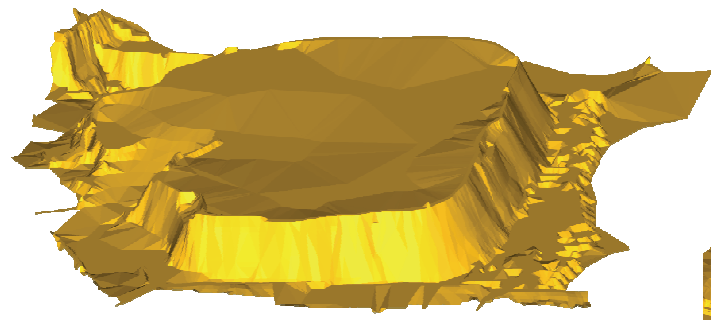

$\%$ Slope area of total area $=25 \%$

$\%$ flat area of total area $=75 \%$

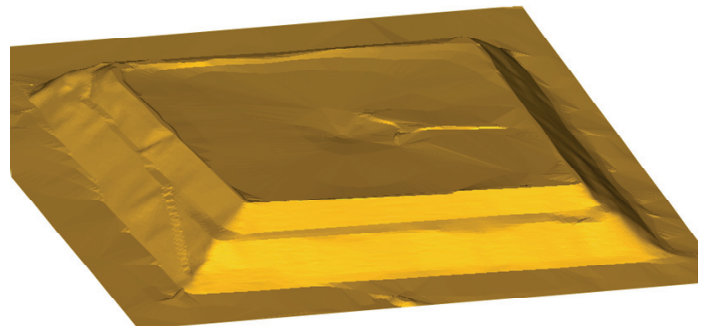

$\%$ Slope area of total area $=51.5 \%$

$\%$ flat area of total area $=48.5 \%$

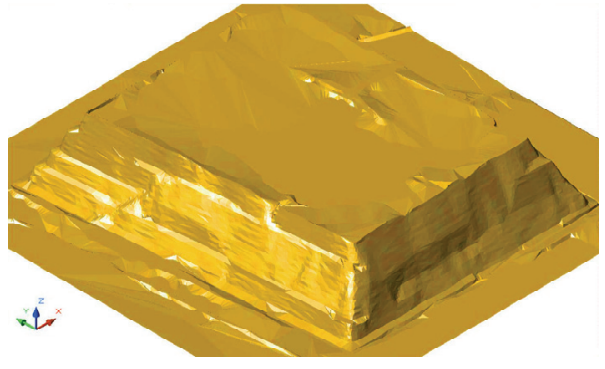

$\%$ Slope area of total area $=43 \%$

$\%$ flat area of total area $=57 \%$

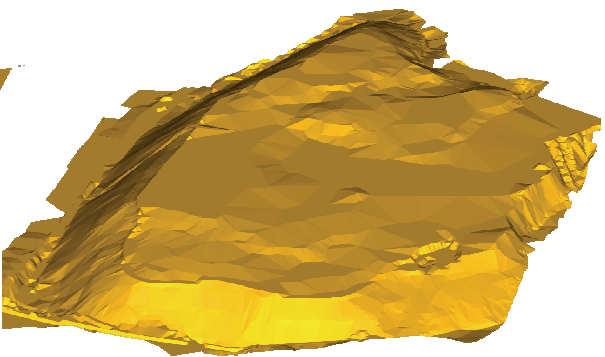

$\%$ Slope area of total area $=41 \%$

$\%$ flat area of total area $=59 \%$

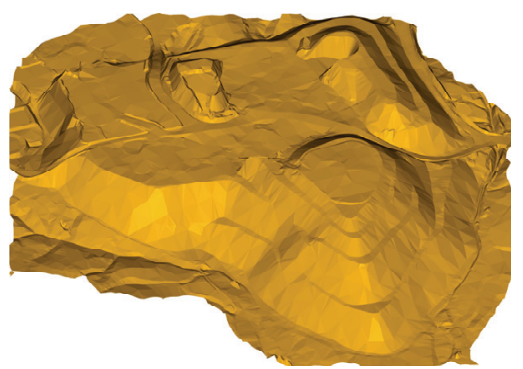

$\%$ Slope area of total area $=58.5 \%$

$\%$ flat area of total area $=41.5 \%$

Figure $1 \quad$ Typical dumps and TSFs - ratios of top surface and slope areas 
However, since store and release covers are, often, placed relatively loosely so as to maximise root growth and water absorption, and cover materials require a certain proportion of fines so as to raise the specific surface area, they can be highly erodable. On slope areas, therefore, it may be necessary to include a rock armouring layer over the cover to provide increased erosion resistance. It will also be necessary to ensure that the residual slopes to be covered are sloped sufficiently to permit machine access and operation to place and spread the cover and armouring materials.

\subsection{Crest Bunds}

It is vital to limit the volume of water flowing down a slope to only that which arises from rainfall directly onto the slope face. The moment a slope has to accommodate runoff from the top surface area of a dump or TSF, erosion rates are accelerated by the flow rate to a power greater than 1.5 and sometimes to the power of 2. This is illustrated by the results of erosion modelling on a typical closed dump in Figure 2.

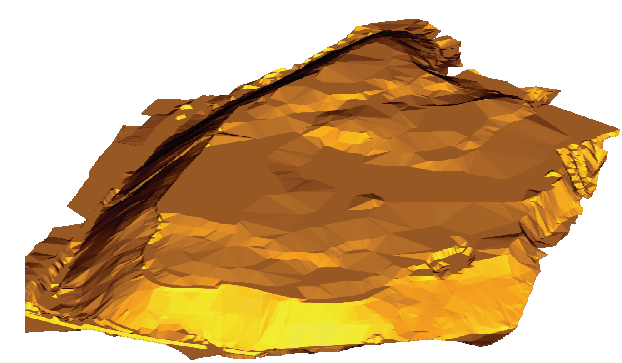

As at closure

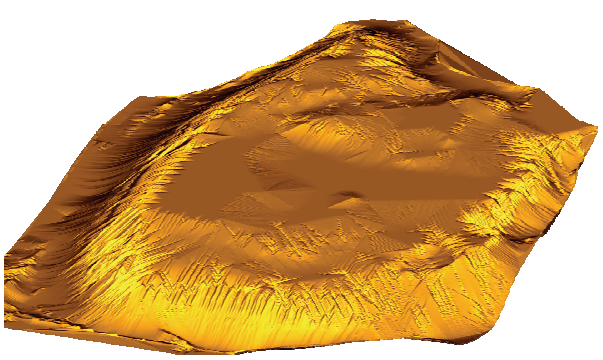

After 50 years

\section{(a) View 1}

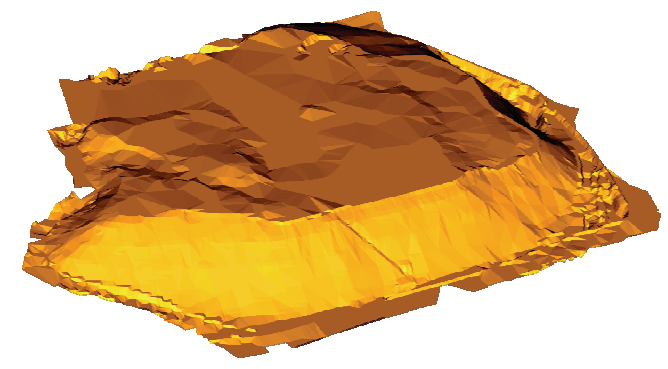

As at closure

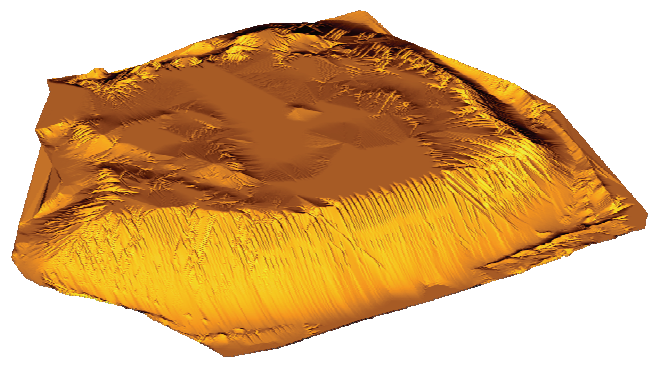

After 50 years

(b) View 2

\section{Figure $2 \quad$ Slope erosion with limited height crest bund after 50 years}

The dump in Figure 2 was finished off with a crest bund of $1 \mathrm{~m}$ and a crest width of $2 \mathrm{~m}$. Once this crest bund had eroded away flow from terraces within the dump were able to flow down the slope. The extent of gulleying is substantial. Figure 3 shows the same dump with a crest bund substantial enough, and suitably profiled, to remain operational over the long term. Dimensions of $3 \mathrm{~m}$ high, $5 \mathrm{~m}$ crest width and 1:4 (v:tt) inside slopes have been applied in the model. In this case the crest berm has successfully prevented run-on from the top surface and, as is evident from Figure 3, the extent of gulley formation and erosion is significantly less. 


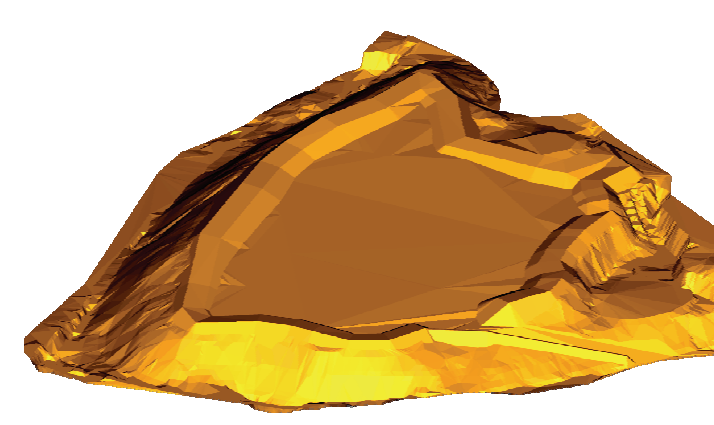

As at closure

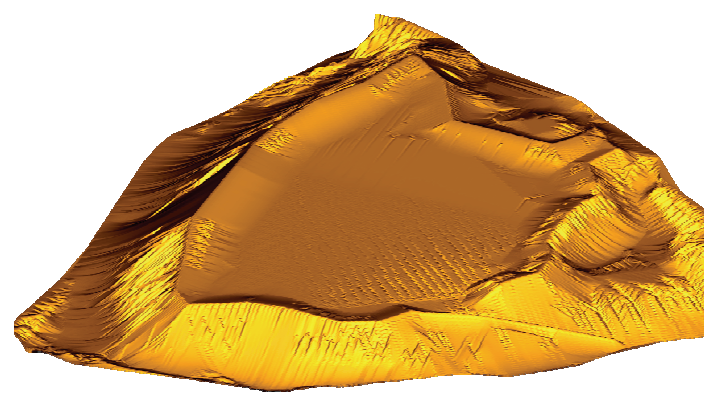

After 50 years

\section{(a) View 1}

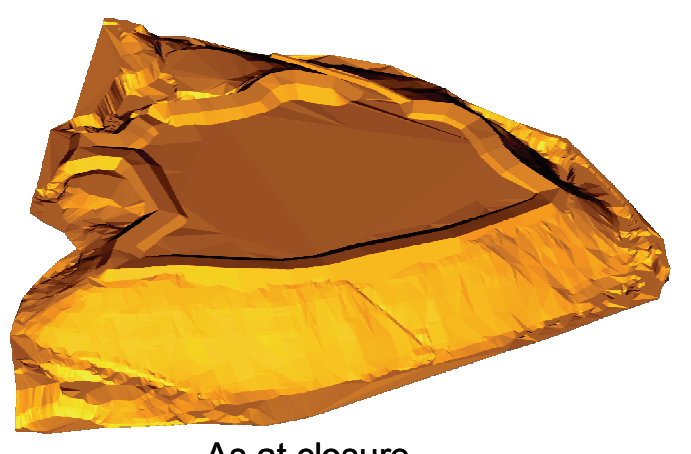

(b) View 2

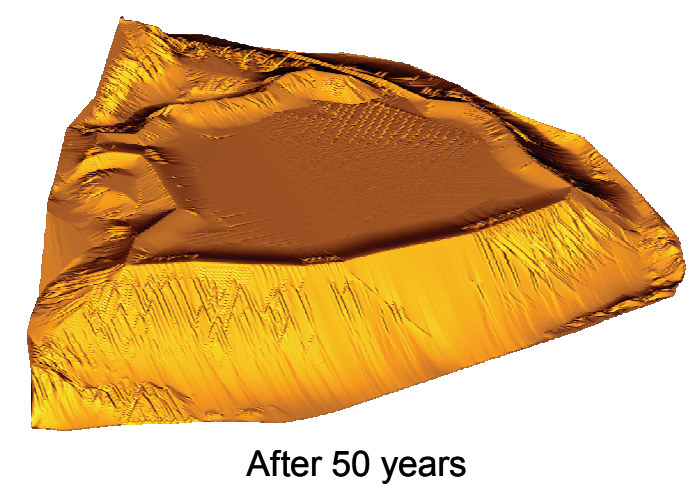

After 50 years

\section{Figure 3 Slope erosion with substantial crest bund after 50 years}

\subsection{Go for flatter, longer slopes - they erode less and are easier to cover}

The flow rate down a slope per unit of slope width is proportional to the slope length and equation 1 can be written:

$$
q_{s}=\beta_{1} q^{m_{1}} S^{n_{1}}-\text { threshold }
$$

Where $q_{s}$ is the mean annual sedimentation rate per unit width of slope and $q$ is the mean annual flow rate per unit width of slope. As noted in Section 2.1, for freshly placed materials, the parameter $n_{l}$ is usually greater than $m_{1}$ which means that the flow rate is more sensitive to the slope gradient than the slope length. It therefore follows that, for freshly placed cover materials and armouring layers, it will be better to adopt a longer flatter slope than a shorter steeper slope notwithstanding the fact that the longer slope will have a greater flow per unit width at the toe of the slope. This is illustrated from the results shown in Figure 4 for modelling of the dump shown in Figure 1, with one part of the main slope at a gradient of 1:3.5 and another at a gradient of 1:4.5.

The depth of erosion on the steeper slope is considerably greater than that on the shallower slope and the spacing of gulleys is considerably closer. Moreover, the depths of the gulleys are more pronounced on the steeper slope. 

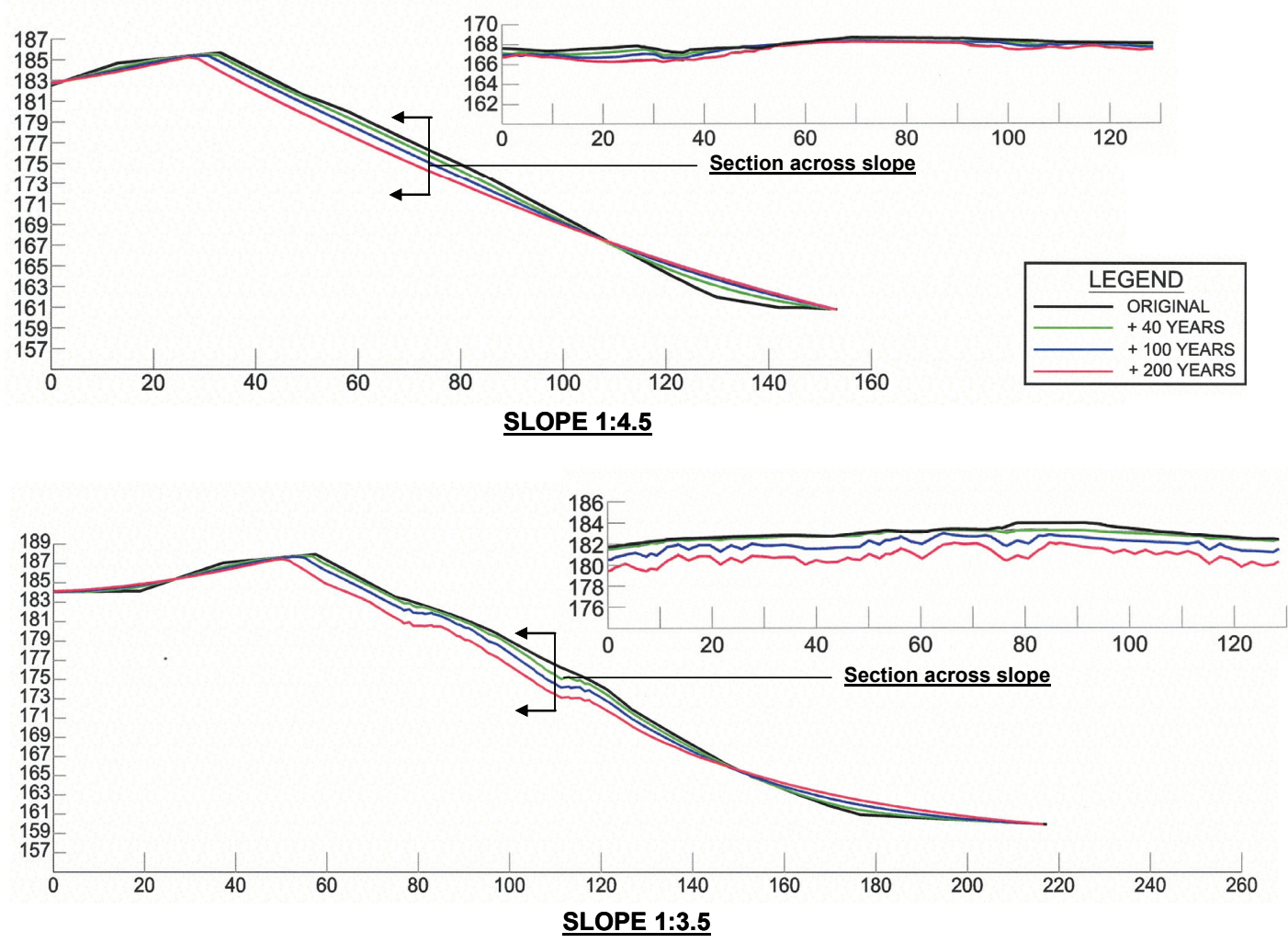

\section{Figure 4 Comparative slope erosion for different slopes}

\subsection{Crest Bunds on Step-backs}

The creation of step-backs has long been held as mandatory slope treatment. Motivations for this approach lie in the need to maintain flatter slopes for slope stability reasons, ease of formation of the step-backs, as well as for decommissioning. However, it is vital to get the dimensional proportions of the step-back and the crest bund to the step back right as material that erodes from the slope above the step-back will progressively fill the void behind the crest bund. With time the crest bund may be overtopped whereupon erosion will accelerate rapidly. This is illustrated in Figure 5 below.

Figure 6 illustrates the results of modelling on the same step-back arrangement but this time with substantially increased crest bund dimensions. The crest bunds have been increased to $2 \mathrm{~m}$ with a crest width of $3 \mathrm{~m}$. It is evident from Figure 6 in comparison with Figure 5 that there is a considerable improvement in erosion performance. 


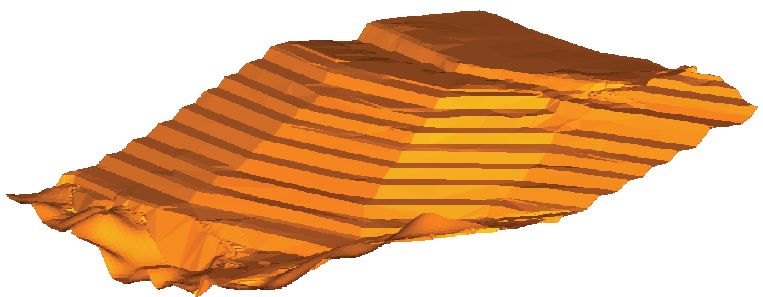

As at closure

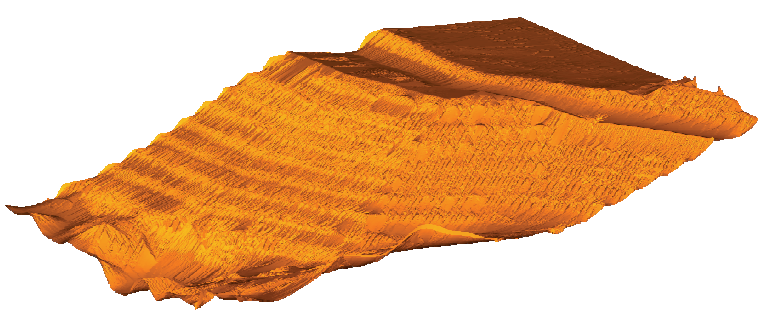

After 40 years

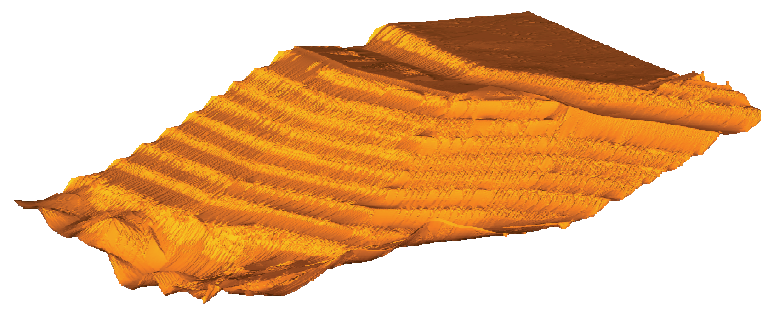

After 20 years

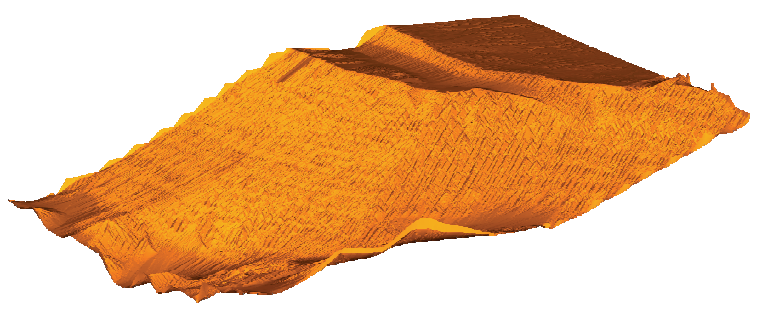

After 60 years

Figure 5 Erosion of step-back slope where crest bunds and step-back widths are not substantial

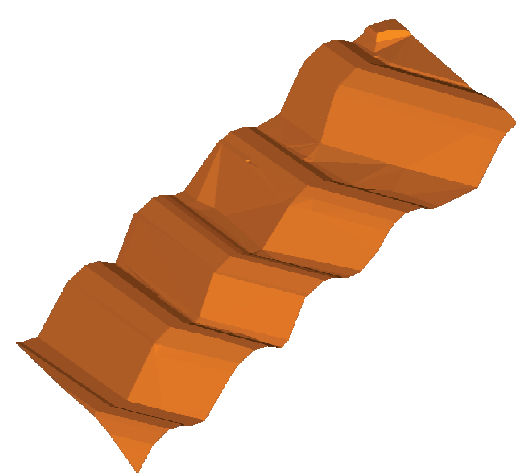

As at closure

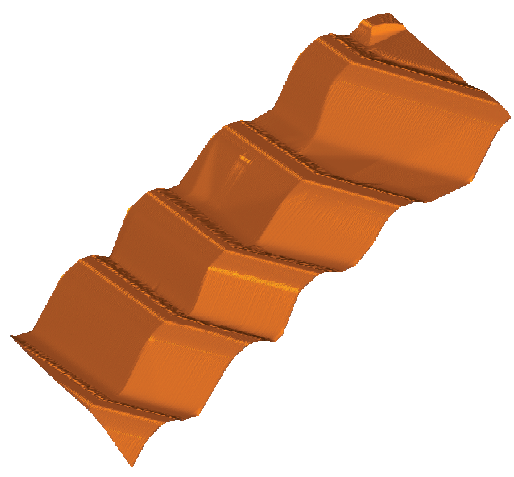

After 40 years

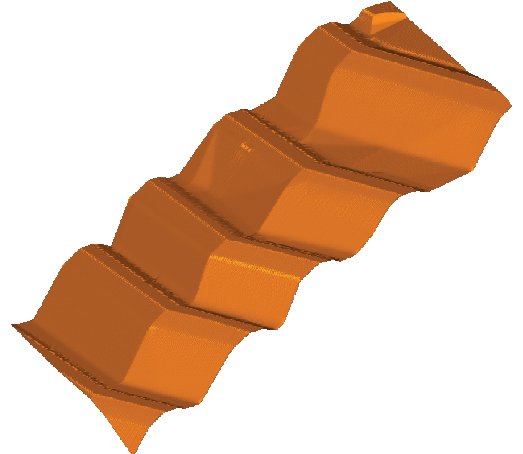

After 20 years

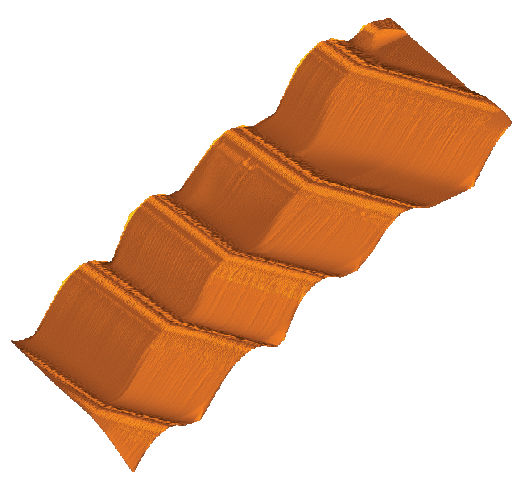

After 60 years

Figure 6 Performance of step-backs with substantial berms and berm crest bunds 


\subsection{Concave Slope Profiles}

Nature as well as the results of erosion modelling, confirm that the total volume of material that will be eroded will be minimised through the adoption at closure of a concave slope profile. It is important to note that erosion will proceed notwithstanding the adoption of a concave profile but over a given time period the total volume of material eroded could be reduced by as much as $50 \%$. Formation of a concave slope is most practically achieved through the formation of suitably sized and spaced step-backs during the dumping process. These step-backs can then be dozed down to form a continuous slope as illustrated in Figure 7.

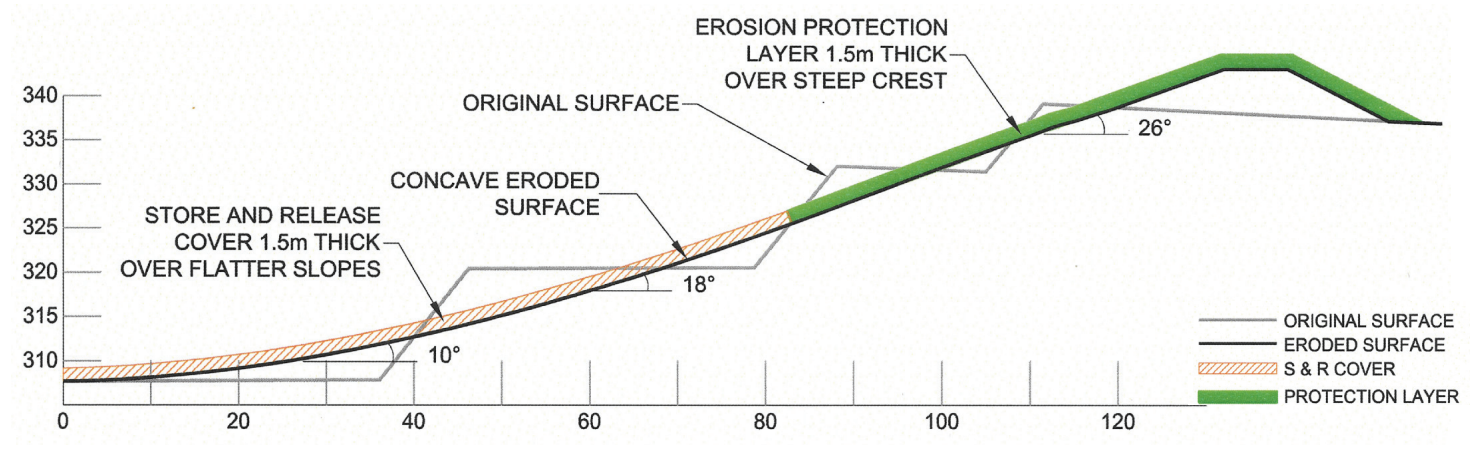

Figure $7 \quad$ Concave slope formation and covering

Depending on the results of erosion modelling it may be necessary to provide erosion protection over the parts of the slope. Figure 7 illustrates erosion protection over the upper, steeper parts of the slope.

\subsection{Covers on Step-backs Need to Take Account of Run-on from the Slopes Above the Step-back}

On existing facilities where step-backs have already been created and it is impractical to doze these slopes down, it will be necessary to hold and pond water on the step-backs. Slopes between the step-backs will most likely be at natural angle of repose of the material and therefore not amenable to application of a store and release cover. Fortunately the runoff rates on these slopes will be high, and infiltration rates low, depending on the length of the slope so a cover may not be as critical as on the step-backs. Unfortunately this means that the store and release cover to be placed in the step-back will need to be more substantial so as to be able to cater for the additional run-on water volume. A potential cover arrangement on the step-back is indicated in Figure 8.

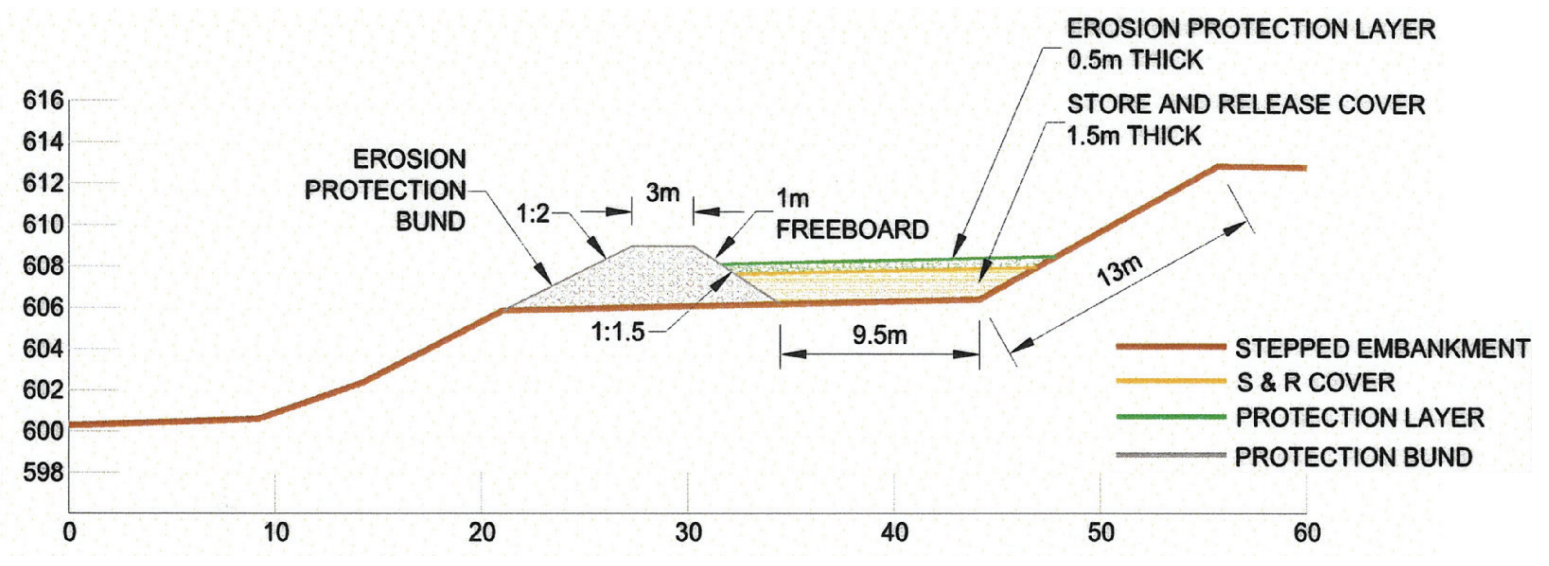

Figure $8 \quad$ Performance of step-backs with substantial berms and berm crest walls

Features of Figure 8 that are noteworthy are the provision of a substantial crest berm to the step-back to cater for the volume of material that will be eroded down as well as for the store and release cover. For this approach to be successful a substantial step-back width will be required as indicated. 


\subsection{Storm Runoff Management}

It is unlikely that it will be possible to provide a store and release cover that is able to absorb high intensity precipitation without generating any runoff. Such runoff has the potential to generate erosion as indicated by the results of erosion modelling on a closed and covered dump shown in Figure 9(a).

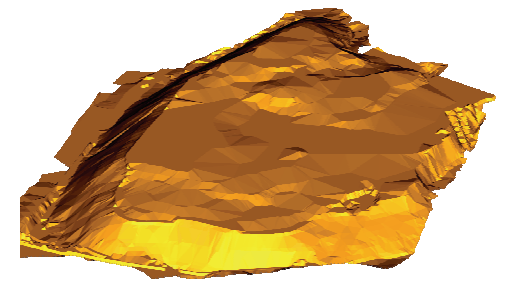

As at closure

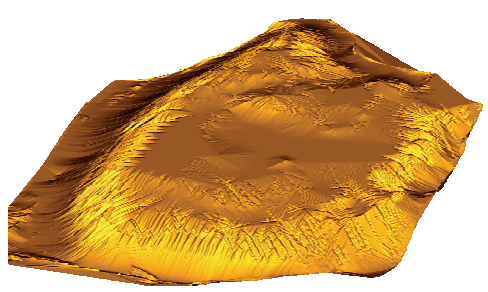

After 200 years

(a) No top surface water management

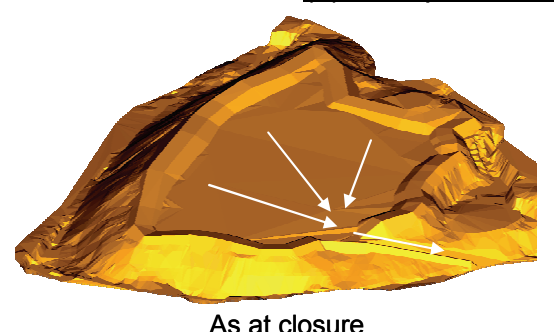

(b) With top surface water management

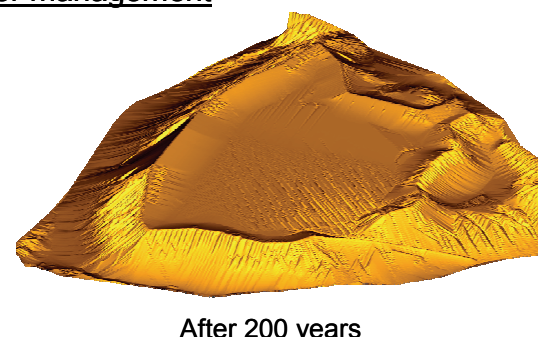

After 200 years

\section{Figure 9 Comparison of erosion with and without management of runoff}

Figure 9(b) shows the results of erosion modelling over the same period as Figure 9(a) on a modified landform for the dump in which flow is directed towards a ramp that is cut down one side of the dump. Care has been taken to ensure that the slope of the ramp is such that the flow remains sub-critical at all times so as to minimise erosion on the ramp itself. Erosion from the slope above the ramp does not significantly impact on the ramp as material eroded from the slope is transported down the ramp. It is evident that management of the water has significantly reduced erosion on the top surface of the dump.

An alternative method of managing runoff on the top surface is to provide storage capacity. In the case of the TSF illustrated in Figure 10(a) water could be controlled in the central area of the TSF within the area occupied by the operating pond. Depending on the nature of the tailings this may be considered to be an acceptable approach since segregating tailings will result in the deposition of the fine, low permeability materials in the pond area. However it should be borne in mind that as these materials dry after decommissioning they will experience considerable shrinkage cracking which will increase the macro permeability of the fine tailings mass. As water pools form in this location hydraulic gradients on the cover will increase and there will be potential for significant net percolation through the cover.

An alternative to this approach that involves paddocking off the top surface of the TSF could be considered. This would have the effect of reducing volumes stored in any single location and therefore reduce hydraulic gradients. The use of paddocks on the top surfaces of TSFs has been a practice used by the South African Chamber of Mines on the closure of abandoned TSFs since the 1970s and has proved successful in partitioning storage with minimal maintenance of the paddock walls. Figure 10(b) indicates the application of this strategy on a TSF and shows that erosion of the paddock walls is manageable. 


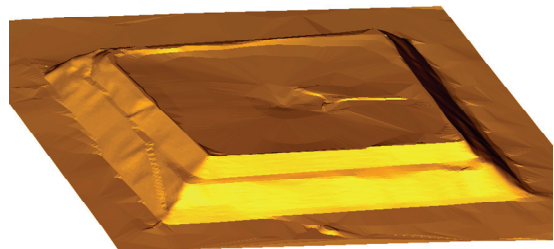

As at closure

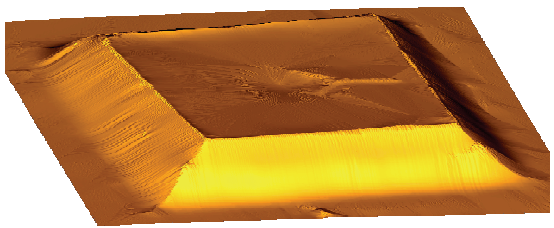

After 200 years

(a) No paddocking

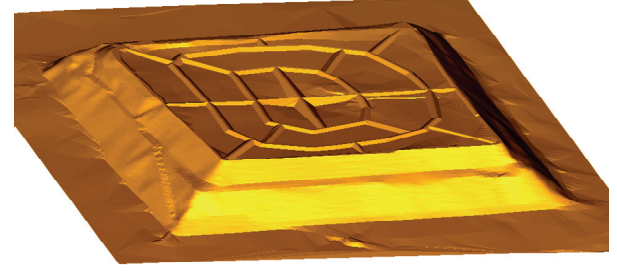

As at closure

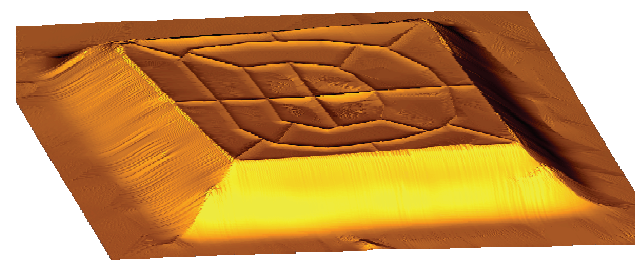

After 200 years

(b) With paddocking

\section{Figure 10 Comparative performance with paddocking}

\subsection{D Modelling with Terrain Adjustment}

An overarching guiding principle in designing landforms suitable for the application of sustainable store and release covers is to evaluate the landform as a whole using 3 dimensional modelling in which the topography changes with progressive erosion. This is the only way to model gulley formation as well as the manner in which gulley development in association with surficial erosion changes the topography of the landform and concentrates erosion. It is the inter-flow between sloped areas on a landform that determines the flow rate at any point. As erosion takes place flow directions can change, flow channels combine and, with ongoing erosion, the topography of the landform will change.

\section{CONCLUSIONS}

In many engineering designs there are inevitably peripheral issues that require optimisation if the primary design is to be effective. Store and release covers are a good example of this. Store and release cover technology and its application is an exciting development worthy of consideration in all appropriate (arid) climates. However, seldom do these climates, regardless of aridity, escape the inevitability of high intensity rainfall and the resulting erosion. Careful landform planning as part of the design of the store and release cover is a peripheral design issue that needs to be carefully optimised if the cover is to live up to expectations. This paper has provided a number of practical guidelines for ensuring that erosion is appropriately managed. However, while the guidelines are useful in directing thinking, they are, in themselves, no substitute for appropriate landform erosion modelling. Changing a landform to control erosion once a cover has been placed at great expense will not be easy and will certainly not be popular with mine management and the accountants.

\section{REFERENCES}

Willgoose, G.R. (2006) Personal communication.

Willgoose, G.R. and Riley, S.J. (1998) Application of a catchment evolution model to the prediction of long term erosion on the spoil heap at Ranger Uranium Mines: Initial analysis. Canberra, Australian Government Publishing Service. Supervising Scientist Report 132. 